\title{
ENSEÑAR HISTORIA, EDUCAR LA TEMPORALIDAD, FORMAR PARA EL FUTURO
}

\author{
Teaching History, Educating Temporality, Training for the Future
}

\author{
Joan Pagès \\ joan.pages@uab.cat \\ Universidad Autónoma de Barcelona. España
}

Fecha de recepción: 17/04/2019

Fecha de aceptación: 17/06/2019

Resumen: El objetivo de este artículo es analizar y valorar la importancia de la enseñanza y el aprendizaje de la historia para la construcción del futuro personal y social de los niños y niñas, de la juventud de nuestras sociedades democráticas. En primer lugar, presentaré el papel que algunos historiadores otorgan al futuro como telón de fondo de las investigaciones sobre el pasado. En segundo lugar, me centraré en aquellas ideas y aquellas propuestas curriculares y educativas pensadas fundamentalmente desde la didáctica de la historia que miran al futuro como el objeto privilegiado la enseñanza de la historia. Y concluiré con la presentación de algunas propuestas curriculares en las que he intervenido y de algunos materiales de los que soy autor, o coautor, en los que las relaciones pasado, presente y futuro son uno de los ejes vertebradores.

El principal valor educativo de la enseñanza de la historia consiste en dotar a los niños y a las niñas y a la juventud de los conocimientos y de las competencias necesarias para ubicarse en su mundo, comprender lo que sucede en él, tener instrumentos teóricos para poder interpretar y valorar lo que sucede, sus antecedentes y sus consecuencias, y para, en definitiva, comprometerles en la construcción de su futuro personal y social. El futuro es el auténtico motor de la historia, el que nos hace tomar decisiones desde un presente que, a su vez, como es sabido, es el resultado de otras decisiones tomadas en el pasado, es decir cuando el presente era futuro.

Palabras clave: enseñanza y aprendizaje de la historia; pensamiento y conciencia histórica; pasado-presente-futuro; historicidad; propuestas y materiales curriculares.

Abstract: The aim of this paper is to analyze and value the importance of teaching and learning history to build children's own personal and social future, the future of young people in our democratic societies. Firstly, l'll present the role attributed by some historians to future as the background for researching about the past. Secondly, I'll focus on ideas and curricular and educative proposals, 
designed from history education point of view, that think of the future as the cornerstone of history teaching. I'll conclude with the presentation of some curricular proposals which I've been part of, and the presentation of some materials I've created, in which the backbones are the relationships between past, present and future.

The main educative value of history education consists on giving children and young people the knowledge and the competences needed to situate themselves in the world, understand what's going on within it, and have the theoretical skills to interpret and evaluate reality, its background and its consequences, to foster commitment in building their own personal and social future. Future is history's real engine, it makes us take decisions form a present perspective, that at the same time are the result of decisions taken in the past when the current present was the future.

Keywords: teaching and learning history; thought and historical consciousness; past-presentfuture; historicity; curricular materials and proposals.

SUMARIO: 1. La historia y el futuro: reflexiones desde la historiografía. 2. La enseñanza de la historia y el futuro. 3. Propuestas y recursos para la enseñanza de una historia para el presente y el futuro de la ciudadanía. 3.1. Reflexiones teóricas sobre la enseñanza del tiempo histórico y del futuro. 3.2. Proyectos y materiales curriculares. 4. Punto final. 5. Referencias bibliográficas.

Hem de recordar que l'articulació temporal de la nostra essència: un present determinat pel propi futur que el passat fa possible, no és una estructura closa; ben al contrari, queda doblement ajornada i t oberta (Gomà, 1988, p. 25) 1 .

Si el futuro no tiene ya futuro es una cuestión que tranquilamente, podemos dejársela al propio futuro (Hölscher, 2014, p. 227).

\section{LA HISTORIA Y EL FUTURO: REFLEXIONES DESDE LA HISTORIOGRAFÍA}

El número de historiadores e historiadoras que en sus trabajos aluden a la importancia del futuro en la construcción del conocimiento histórico es cada vez mayor. En realidad, señalan al presente como el principal referente de su trabajo sobre el pasado. E, inevitablemente, el presente se proyecta hacia un futuro que construimos desde el mismo presente (véanse, por ejemplo, las respuestas dadas por historiadores e historiadoras francesas en un programa de radio de Laurentin (2011) a la pregunta «¿Para qué sirve la historia hoy?».

Las principales aportaciones que los y las historiadores consideran que el estudio del pasado puede tener para el futuro de los ciudadanos y de las ciudadanas pueden, según mi análisis, clasificarse en dos bloques. En primer lugar, las que en-

1 Debemos recordar que la articulación temporal de nuestra esencia: un presente determinado por el propio futuro que el pasado hace posible, no es una estructura cerrada; por el contrario, queda doblemente aplazada y abierta. Esta, y el resto de traducciones, son responsabilidad del autor de este artículo. 
señan a ubicarse ante el futuro y nos preparan para intervenir en su construcción. En segundo lugar, las que nos alertan de lo que podría suceder si se desconoce lo que ya ha pasado o nos facilitan ejemplos frente a determinados problemas del presente que ya fueron problemas en el pasado.

El carácter prospectivo del estudio de la historia nos permite aprender a pronosticar (Prost, 2016), a plantear expectativas realistas (Koselleck, 1993), a presentar alternativas (MacMillan, 2010), a desarrollar el pensamiento prospectivo para la construcción del futuro (Guldi y Armitage, 2016; Fontana, 2013), etc. Pero también nos prepara ante los riesgos de asumir la creencia de que solo hay una manera de mirar las cosas o un único camino (MacMillan, 2010). Nos ofrece ejemplos para denunciar y terminar con la marginalidad de personas o grupos y con las injusticias (MacMillan, 2010), nos da ejemplos e ideas para atacar y menospreciar a los demás (MacMillan, 2010) o, sencillamente, nos dota de herramientas para hacer frente a las mentiras, los mitos o los ruidos existentes en el presente (Guldi y Armitage, 2016).

Guldi y Armitage (2016), por ejemplo, explicitan la relación pasado, presente y futuro como una relación necesaria ante los retos que las sociedades tienen ante sí y como guía para trazar aquellos caminos que mejor les convengan. Para estos autores «una función importante [de la historia es actuar] como árbitro para determinar la falsedad, el mito y el ruido en una época abrumada de big data, en la que el riesgo futuro adopta la forma de problemas a una escala sin precedentes, como son el cambio climático y la gobernanza trasnacional» (p. 223). Y añaden que el estudio del pasado «proporciona una hoja de ruta al pensamiento prospectivo de todas aquellas instituciones - de gobierno, de las finanzas, los seguros, informales, de auto organización, científico-ciudadanas y otras- a las que acudimos para que nos guíen en nuestra búsqueda del camino hacia mejores futuros». Para estos autores, «El pasado, creemos, es el mejor indicador del comportamiento futuro de todas [las tradiciones]» (p. 225).

El sentido de orientación, de proyección, era fundamental para Fontana (2013) en su trabajo El Futuro es un país extraño. Para este historiador, recientemente fallecido, su papel como historiador «es el de ayudar a denunciar la mentira de unos análisis tramposos que pretenden incitarnos a la resignación, para contribuir, en la medida de sus fuerzas, a la tarea de reinventar un nuevo futuro, que es todavía un país desconocido, una vez arruinadas las posibilidades de realizar el viejo» (p. 20). Fontana concluye su análisis Ilamando a la ciudadanía a «renovar lo que se combate» y a «inventar un mundo nuevo que pueda ir reemplazando al actual, que tiene sus días contados» (p. 153).

La invención de un mundo nuevo, como consecuencia de la importante crisis social retratada por Fontana, es el reto y es el legado del estudio del pasado. De una opinión parecida es Christian (2005) para quien la "gran historia» no se detiene en el presente, sino que «plantea por fuerza preguntas sobre el porvenir». "Plantear 
estas preguntas debería ser en nuestros días una parte esencial de la educación, ya que las valoraciones que hagamos del futuro afectaran a las decisiones que tomemos en la actualidad: estas, a su vez, influirán en el estilo del mundo que habiten nuestros hijos y nuestros nietos». La frase termina con la siguiente premonición: «No nos darán las gracias si nos tomamos este cometido a la ligera» (p. 26).

Cada vez son menos los historiadores o las historiadoras que se lo toman a la ligera. Al contrario. Para MacMillan (2010), por ejemplo, «el peligro es que no prestemos la atención suficiente a los problemas arduos de hoy en día» (p. 45). Afirma esta historiadora: «Discutimos sobre la historia porque puede tener un significado real en el presente. $Y$ la usamos de muchas formas: para movilizarnos y conseguir objetivos de futuro, para hacer reclamaciones (de tierras, por ejemplo) y desgraciadamente también para atacar y menospreciar a los demás. Examinar el pasado puede ser una especie de terapia si descubrimos cosas de nuestra propia sociedad que habían pasado inadvertidas o reprimidas. Para aquellos que no tienen poder o que sienten que no lo tienen en la medida suficiente, la historia puede ser una forma de protestar contra su marginalidad, o contra tendencias o ideas que no les gustan, como la globalización. Los casos en los que salen a la luz injusticias o crímenes del pasado se pueden usar para buscar una reparación en el presente. A todos, poderosos o débiles por igual, la historia nos ayuda a definirnos y reivindicarnos» (p. 65).

Los usos sociales del conocimiento histórico para el presente y para el futuro son, como pone de relieve esta autora, muchos y muy variados, a pesar como también afirma que «en la historia no encontraremos planos claros que nos ayuden a moldear el futuro tal como lo deseamos. (...) Sin embargo, examinando el pasado podemos obtener ejemplos útiles para saber cómo proceder, y si es probable o no que ocurra algo» (p. 172).

MacMillan cree que la historia puede ayudar a la ciudadanía a ser más sabia. "La historia, si se usa con cuidado, puede presentarnos algunas alternativas, ayudarnos a formular las preguntas que necesitamos hacernos en el presente, $y$ advertirnos de lo que puede fallar». (p. 173). Puede, además,

(...) ayudarnos a desentrañar un mundo complicado, pero también nos puede advertir del peligro que representa asumir que solo hay una forma posible de mirar las cosas, o un curso de acción determinado. Siempre debemos estar dispuestos a considerar alternativas y a poner objeciones. No debemos dejarnos impresionar cuando nuestros líderes nos dicen, firmemente, "la historia nos enseña esto» o «la historia demostrara que tenemos razón». Pueden simplificar y forzar comparaciones inexactas, igual que podemos hacer cualquiera de nosotros. Hasta los más listos y los más poderosos (y ambos no tienen por qué ser los mismos) transitan confiadamente por caminos erróneos. Es muy útil también recordar como ciudadanos, que los que se encuentran en puestos de autoridad no siempre conocen mejor las cosas (p. 190). 
Una seria advertencia a la ciudadanía del poder que tiene saber historia y, contrariamente, de la gravedad de ignorarla. El presente determina tanto la mirada hacia el pasado como la utilización del pasado para la construcción del futuro. Tal vez por esta razón, Lowenthal (1998) consideraba que ambos eran inaccesibles. "Sin embargo -afirmaba-, aunque estén fuera del alcance físico, forman parte de nuestras imaginaciones. El recuerdo y la expectativa cubren cada momento presente» (p. 27).

A la expectativa, al pronóstico, se refirió Prost (2016), al afirmar que "el pronóstico, que se dirige desde el presente al futuro, se basa en el diagnostico extraído del pasado para augurar evoluciones posibles y evaluar sus respectivas probabilidades» (p. 87). Al pronóstico, no a la profecía, se llega a través del desarrollo del pensamiento y de la conciencia histórica. Rüsen (2007) al analizar la relación entre memoria e historia y entre pasado, presente y futuro alerta de los riesgos de una memoria anclada en el pasado. Para este autor,

La memoria presenta el pasado como una fuerza que mueve el pensamiento humano guiada por principios de uso práctico, mientras que la conciencia histórica representa el pasado interrelacionándolo de manera explícita con el presente, guiada por conceptos de cambio temporal y por reclamaciones veraces: acentúa la temporalidad inequívoca del pasado como una condición para su relevancia para el presente. La memoria es una relación inmediata, y la conciencia histórica es una relación mediata, entre el pasado y el presente. La memoria está relacionada más con el reino de la imaginación, la conciencia histórica más con el de la cognición. La memoria está atascada en el pasado; la conciencia histórica abre esta relación al futuro.

Tal vez esta es la razón por la que Koselleck (1993) afirma, al reflexionar sobre las relaciones entre la experiencia y la expectativa, que «son dos categorías adecuadas para tematizar el tiempo histórico por entrecruzar el pasado y el futuro» ( $p$. 337). Según este autor «la expectativa se efectúa en el hoy, es futuro hecho presente, apunta al todavía-no, a lo no experimentado, a lo que solo se puede descubrir» (p. 338). Pero «El pasado y el futuro no llegan a coincidir nunca, como tampoco se puede deducir totalmente una expectativa a partir de la experiencia» (p. 339), aunque «debe poder salvarse también la diferencia entre experiencia y expectativa hasta el punto de que se pueda concebir de nuevo la historia como susceptible de ser enseñada» (p. 357).

Un ejemplo de esta historia "susceptible de ser enseñada», en la que se relaciona investigación con docencia y experiencia con expectativa nos la ofrece Gruzinski (2018). Este autor relata la experiencia vivida por un grupo de estudiantes de 15 y 16 años del liceo Jean Rostand de Roubaix - "Esta ciudad, de la que se dice que es la más pobre de Francia, ocupa un lugar singular en la historia de las poblaciones francesas surgidas de la inmigración» (p. 32) y que, actualmente, «se ha convertido, según dicen, en el municipio más musulmán de Francia» (p. 33)- que estudiaron 
y dramatizaron «dos historias paralelas que se desarrollaron a comienzos del siglo XVI: la conquista de México por los españoles y la incursión de los portugueses en China» (p. 30), ambas investigadas por él.

Los resultados de la experiencia son altamente valorados por este historiador que, además, da la palabra al docente que supo predisponer a un alumnado con pocas expectativas a descubrir el valor y el uso del conocimiento histórico. Para Laurent Guitton (2018), el promotor de esta experiencia,

Los alumnos no solo han sido actores de su aprendizaje escolar sino también, y durante un tiempo, protagonistas de una historia universal e historiadores noveles, capaces de acceder por sí mismos a una forma de escritura de la historia. Al rebasar el relato nacional, que por sí solo no bastaba para conferir sentido a su recorrido familiar y social, esta historia de las conquistas ibéricas permite ofrecer a un público escolar de diversos orígenes culturales una visión crítica y distanciada de una mundialización cada vez más compleja, con el fin de prepararlos mejor para su futuro papel de ciudadanos del mundo (p. 243).

\section{LA ENSEÑANZA DE LA HISTORIA Y EL FUTURO}

Preparar a los y a las jóvenes estudiantes para «su futuro papel de ciudadanos del mundo» ha sido una de las principales finalidades de aquellos y aquellas docentes que han creído que la enseñanza de la historia debía aportar algo más que lo que proponían los currículos y los programas basados en las historias nacionales y eurocéntricas y en la memorización de hechos y personajes relevantes de su pasado. Ha sido la preocupación fundamental de quienes han apostado, y siguen apostando, por la formación del pensamiento y de la conciencia histórica y por la acción transformadora que sus saberes pueden facilitar a la ciudadanía.

Las reflexiones sobre la enseñanza de la historia de un importante grupo de pedagogos, psicólogos y didactas han puesto el énfasis en la importancia del presente $y$, en menor medida, también del futuro como finalidad y objetivo última de esta enseñanza. Con poco éxito, sin duda. Pero ya desde tiempos de John Dewey, y otros pioneros, se abrió un camino que, posteriormente, otras y otros didactas y docentes han seguido desde la didáctica de la historia.

¿Por qué el presente y el futuro debían ser una finalidad del estudio del pasado? Por razones parecidas a las que hemos visto en el caso de los historiadores e historiadoras. $Y$, tal vez algunas más referidas a la importancia de preparar a la ciudadanía para participar activamente en la construcción de su futuro personal y social a través del desarrollo de su pensamiento histórico. Para Dewey (1985), por ejemplo, el pasado debía ser considerado un recurso para el desarrollo del futuro. Este autor consideraba, a principios del siglo $x x$, que 
La segregación que mata la vitalidad de la historia consiste en separarla de las formas y de los intereses de la vida social del presente. El pasado como pasado ya no es más cosa nuestra. (...) Pero el conocimiento del pasado es clave para entender el presente. (...) los hechos del pasado no se pueden separar de la actualidad viva sin perder significado. El punto de partida verdadero de la historia siempre es una situación presente problemática (p. 155).

De una opinión parecida fue Hinsdale (1912), otro profesor norteamericano, quien al analizar el valor educativo de la historia en su tiempo ponía el énfasis en la formación del pensamiento para la toma de decisiones ante los retos del futuro:

Si los hechos del pasado son pensados simplemente o principalmente para ser recordados; si el maestro considera al discípulo simplemente como un receptáculo que llenar; si la única ambición del estudiante es «conocer» una gran cantidad de historia, entonces los poderes de análisis, comparación e inferencia solo serán débilmente desenvueltos. Aún más, el espíritu tomará una orientación conservadora, mirará hacia atrás más bien que adelante y no poseerá iniciativas útiles en los negocios prácticos (p. 42).

Más recientemente, desde los supuestos teóricos de la Escuela Nueva, de la Escuela Activa, del movimiento Freinet, o desde la teoría crítica y desde la didáctica de la historia se ha apostado por tener el futuro como referente.

Esta era la opción por la que apostaron, en Argentina, por ejemplo, Bollo de Romay y Benzrihem (1963) quienes consideraban que «Para la juventud actual, la Historia sin un proyectarse hacia delante es letra muerta. Solo interesan los procesos en tanto ayudan a interpretar la realidad actual, y en cuanto dejen entrever la posibilidad de un mundo futuro menos inestable y más feliz (p. 5). Y ello a pesar de tener que trabajar con un programa de historia más bien clásico. Un programa clásico que, para Nidelcoff (1979) era claramente ideológico pues «a través de la Historia (...) transmitimos a los niños una visión del pasado que es la del sector social que se impuso sobre los otros. Estos últimos son ignorados o presentados como seres temibles o 'barbaros', son 'los malos' de nuestra Historia» (p. 15). Para ello el maestro - «el maestro pueblo», no el «maestro gendarme»- ha de "ayudar al pueblo a descubrirse, a expresarse, a liberarse», es decir "quiere contribuir a crear hombres nuevos y a alumbrar una sociedad nueva, donde se dé la promoción de los desposeídos, donde el pueblo sea el protagonista» (p. 17). La denuncia del carácter ideológico de la historia que se enseña va acompañada de una propuesta centrada en otros saberes y en otros métodos a fin de que el "maestro pueblo» ayude al alumnado a "desarrollar su sentido crítico frente a la realidad» (p. 76) y pueda proyectarlo hacia su futuro. Este es el reto del profesorado francés de historia y geografía de ICEM-Pédagogie Freinet (1984) para quienes «Construir conscientemente 
el futuro es la responsabilidad histórica de todos. La historia y la geografía pueden contribuir a su nivel: aparecen como un anti-destino, un arma absoluta contra el fatalismo y la resignación» (p. 31).

También a la búsqueda de soluciones dedicó sus reflexiones y sus propuestas Evans (1996). Para este autor, la situación de la enseñanza de la historia en los Estados Unidos - «En algunas, en pocas clases, la historia se convierte en una fuente de reflexión sobre las elecciones que hemos hecho en el pasado y las decisiones que tomaremos en el futuro» (pp. 152-153)-, le conduce a proponer una enseñanza centrada en la reflexión crítica de la sociedad que pueda contribuir a su transformación hacia mayores niveles de democratización y de justicia social. Cree que la enseñanza de la historia de los USA debería priorizar como objetivo central «la reflexión crítica sobre el pasado, el presente y el futuro» (p. 152). Sugiere que en el desarrollo de los temas la perspectiva crítica sea trabajada en profundidad rompiendo la estructura cronológica. En su opinión, solo así es posible relacionar de manera adecuada los problemas sociales del pasado y del presente con el futuro especialmente en la escuela superior. Ilustra su propuesta en temáticas tales como "la raza y la etnicidad como obsesión americana», "las clases sociales en América», «el género y la sexualidad en la vida americana», o «el poder en América», entre otras. Estos temas, en su opinión, ejemplifican una concepción del currículo de historia dirigida a la educación para la acción social y, en consecuencia, dirigida al futuro.

El futuro es, sin duda, el motor de la historia que se enseña. El futuro como esperanza, como el tiempo no construido que ha de permitir a los y a las jóvenes ser ellos y ellas mismas. Audigier (1999) considera que la historia enseñada, como la educación cívica, dependían de un proyecto de futuro. Y lo mismo consideran Arthur, Davies, Wrenn, Haydn y Kerr (2001). Para estos autores, el conocimiento y la comprensión histórica son absolutamente centrales en la educación ciudadana, en especial para comprender los problemas contemporáneos y para el desarrollo de habilidades. En su opinión, «El pasado es la estructura en la que se proyecta la ciudadanía; es el trampolín desde el que los ciudadanos aprenden a pensar y a actuar» (p. 161).

Las relaciones entre el pasado, el presente y el futuro han de presidir la enseñanza de la historia. Arthur, Davies, Wrenn, Haydn, Kerr (2001) creen que

para que los estudiantes den sentido a la perspectiva política enseñada rigurosamente en las lecciones de historia, necesitan relacionar este aprendizaje con el presente. El peligro de la historia como disciplina escolar es que, si los profesores de historia no pueden hacer relaciones y comparaciones entre pasado y presente, los estudiantes pueden no comprender el rol que juega el pasado en dar forma a su propia existencia y por tanto a su futuro como ciudadanos. Las relaciones entre el desarrollo político del pasado y la política actual necesitan ser explícitas. Cerrar este vacío entre la enseñanza de la historia y los acontecimientos actuales puede ser relativamente sencillo (p. 75). 


\section{PROPUESTAS Y RECURSOS PARA LA ENSEÑANZA DE UNA HISTORIA PARA EL PRESENTE Y EL FUTURO DE LA CIUDADANÍA}

Las relaciones entre el pasado, el presente y el futuro han constituido uno de los ejes de mi trabajo como docente y como didacta de la historia. He procurado que mis propuestas se insertasen dentro de la historia y la didáctica de la historia como he puesto de relieve en los dos apartados anteriores. Mi intención ha sido siempre clara: la historia debía ser útil a los niños y niñas, a la juventud, para construir su historicidad y desarrollar su pensamiento y su conciencia histórica o no valía la pena hacerles perder el tiempo.

Mis propuestas están acompañadas de un conjunto de reflexiones teóricas que me han permitido ubicarlas tanto en la investigación histórica como en la investigación didáctica. En este apartado presentaré en primer lugar estas propuestas para, en el segundo, ilustrarlas con algunos ejemplos y con algunos recursos curriculares.

\subsection{Reflexiones teóricas sobre la enseñanza del tiempo histórico y del futuro}

En mi primer trabajo sobre la enseñanza del tiempo histórico (Pagès, 1988) me planteaba definir qué era el tiempo histórico y cómo debían enfocarse, desde la enseñanza de la historia, las relaciones entre el pasado y el presente y el papel que el futuro debía tener en ella. Definía el tiempo social como

el tiempo de las sociedades en su evolución, de los hombres y de las mujeres que transforman la realidad y la crean conscientemente. El tiempo social es el tiempo histórico, es el tiempo del pasado, del presente y del futuro de las sociedades. Es el resultado de las acciones y de las obras que el pasado proyecta en el presente y que avanzan, lenta o rápidamente, pero de manera continua hacia el futuro (p. 12).

En este mismo trabajo advertía de los riesgos de una enseñanza de la historia centrada en el pasado por el pasado, al margen del significado social para el presente y para el alumnado de los hechos a estudiar, y de la identificación del tiempo histórico con el tiempo cronológico al considerarlo como una realidad homogénea y lineal. Frente a esta concepción presentaba «un tiempo plural que varía según la realidad a la que se refiera y según el colectivo o grupo humano al que se aplica» (p. 13) y proponía articular la enseñanza y el aprendizaje de la temporalidad siguiendo a Johnson (1976) en las siguientes categorías: el alejamiento y la evocación, la cronología y la periodización, los cambios y la evolución causal y los ritmos evolutivos y las duraciones. Apostaba, además, por la combinación de una aproximación sincrónica, con una aproximación diacrónica, temática, siguiendo las pautas de Jeffreys (1959) y de Cousinet (1971-1972) o de la utilización del tiempo histórico que hacen la mayoría de las ciencias sociales. Afirmaba que la función fundamental de 
la historia y del tiempo histórico había de ser la comprensión de la actualidad, para lo cual debía ofrecer a la ciudadanía los medios necesarios para que pudiera definir sus proyectos personales y su participación en proyectos sociales. Y concluía con una referencia explícita al futuro:

La presencia del futuro en el presente, socialmente asumida y cronológicamente bien situada en unas fechas que casi se han convertido en mágicas $-1992^{2}$ y 2000 han de estimular nuestra imaginación de profesores en la elaboración de recursos y actividades que relacionando el pasado que tenemos presente con el futuro, que también es presente, abran vías a nuestros alumnos para la participación consciente y activa en la construcción de la sociedad del futuro, en la construcción de su propio tiempo (Pagès, 1988, p. 16).

En un trabajo posterior concreté algunas de las ideas de este primer trabajo en una propuesta curricular para enseñar el tiempo histórico (Pagès, 1989). Esta propuesta estaba presidida por una cita del profesor de filosofía de la Universidad de Barcelona, el Dr. Gomà (1988), que desde entonces he utilizado para justificar la importancia de la enseñanza de la temporalidad: "La asunción del pasado hace posible el futuro que precisamente ahora determina mi presente». En este trabajo criticaba el tratamiento que se daba al tiempo histórico en los programas de historia tradicional. «En los diseños de lo que denominamos la historia tradicional (...) La relación presente-pasado-futuro no es más que un enunciado que difícilmente se concreta en la práctica, pues el presente casi nunca constituye el referente obligado para acercar a los alumnos al pasado a partir de los interrogantes y de los problemas que plantea» (p. 118).

Planteaba algunos modelos alternativos que iban desde la propuesta diacrónica belga para la enseñanza de la historia en secundaria (Hodeige, 1981) a la historia retrospectiva propuesta por la profesora argentina Simián de Molina (1970). Y concluía con una propuesta de actividades entre las que destacaba una unidad didáctica sobre Las etapas de la historia y el pasado que tenemos presente que desde entonces he ido puliendo y mejorando. Esta unidad didáctica actúa de epítome inicial de cualquier curso de historia y tiene como objetivo ubicar los antes y los después en relación con el presente y con lo que se estudió en el pasado o se estudiara en el futuro. Uno de los principios que presiden esta unidad el siguiente: «1. El presente es una consecuencia del pasado y se proyecta hacia el futuro. El futuro será el resultado de las acciones y decisiones que tomemos en el presente, de la misma manera que el presente lo es de las que se tomaron en el pasado» (p. 127).

2 El año 1992 fue el año de los Juegos Olímpicos de Barcelona y la ciudad, y con ella todos sus habitantes, estaba movilizada desde el momento que se conoció su elección como ciudad olímpica. El año 2000 era el referente temporal del cambio de siglo. 
La primera actividad de esta unidad consiste en solicitar al alumnado la redacción de una carta dirigida a un muchacho o muchacha de su misma edad que viva en su misma localidad, pero en el año 2230 , por ejemplo. Se trata de indagar qué representaciones tiene de su mundo y de sus orígenes a través de un relato dirigido a una persona que vive en el futuro y a quien debe situar sobre las principales características del mundo a día de hoy, de un mundo muy diferente al suyo. Buena parte del resto de las actividades se realizan a través de la observación de unas imágenes de la evolución de una ciudad europea desde sus orígenes hasta la actualidad, y al revés, y del análisis de evidencias de las distintas etapas ${ }^{3}$. El futuro no acababa, sin embargo, de ser objeto de una enseñanza explícita más allá de propuestas del estilo "cómo te gustaría que fuera...». Sí estaba presente, en cambio, en las intencionalidades de la propuesta tal y como explicité en las conclusiones finales:

"Sin embargo, el tiempo avanza y los futuros van tomando, inevitablemente, cuerpo en el presente. El reto es claro: ¿en qué medida la construcción del futuro será una consecuencia de lo que sepan del pasado nuestros actuales alumnos?» (p. 134). Respondía a este interrogante recurriendo de nuevo a Gomà e incorporando las palabras del historiador catalán Josep Fontana (1988) cuando en relación con la enseñanza de la historia afirmaba que esta ha de poner al descubierto que en el pasado el hombre "tenía diversas posibilidades y hubo de escoger entre diversos futuros -que son nuestros presentes- ninguno de los cuales era el único posible, inevitable», de la misma manera que "en el presente no tiene un único camino para escoger, sino varios, y su futuro dependerá de cuál sea el que elija» (p. 30).

Algunas de estas ideas fueron retomadas posteriormente. En un trabajo publicado en 1997 (Pagès, 1997a) me posicioné ante el debate protagonizado por la Real Academia de la Historia y la Ministra de Educación del gobierno conservador del Sr. Aznar, la Sra. Esperanza Aguirre (1996). Su defensa de la historia escondía un uso social al servicio de los valores dominantes y de una concepción positivista del saber histórico que rechazaba el presente y escondía el futuro. Para la Ministra,

${ }^{3}$ Recientemente he tenido la ocasión de construir un modelo alternativo al eurocéntrico para estudiar la evolución de un territorio y de una comunidad latinoamericana, en concreto chilena, a partir de las transformaciones producidas desde sus orígenes a la actualidad. La periodización es radicalmente distinta a la clásica eurocéntrica. He utilizado para ello las imágenes del trabajo de Alicia Hoffman y Raquel Echenique (2011). El alerce, gigante milenario. Editorial Amanauta. Estas autoras presentan la evolución de un territorio situado en el Sur de Chile, entre Puerto Montt, Chaitén y la Isla Grande de Chiloé desde finales del último período glacial (hace unos 13000 años) hasta el siglo XXI. En imágenes visibilizan las transformaciones producidas desde el siglo xvi con la llegada de los españoles y en los siglos XVII, XVIII, XIX y XX-XXI que permiten plantear los cambios y las continuidades y los futuros previsibles en cada corte, $\mathrm{e}$ indagar en las causas de los mismos. 
(...) lo más grave -sin que el delirante léxico pedagógico al uso sea cosa de poca importancia- es la escasez de contenidos históricos en la enseñanza que reciben nuestros escolares. Un alumno puede atravesar por entero sus diez años de escolarización obligatoria sin escuchar ni una sola vez una lección sobre Julio César o sobre Felipe II. En la enseñanza obligatoria la historia se ha reducido a un somero estudio de la Edad Contemporánea por no decir lisa y llanamente del mundo actual. La cronología, a la que se ha definido con acierto como el esqueleto de la Historia, brilla por su ausencia. Y el estudio de las grandes personalidades históricas se ha visto reemplazado por un análisis de las estructuras tratado bajo la óptica metodológica, no de la Historia, sino de las Ciencias Sociales (p. 3).

No solamente eran falsas estas apreciaciones, como puede comprobarse consultando el currículo aprobado por el gobierno socialista de Felipe González y que desarrolla la LOGSE (1990), la primera ley democrática de educación de la historia de España, sino que además encerraban todo un programa de política educativa muy en consonancia con lo que habían hecho en sus respectivos países la Sra. Tatcher o los Bush en relación con la enseñanza de la historia. En 1998 tuve ocasión de volver a terciar sobre este debate -en realidad, el debate de las finalidades de la enseñanza de la historia- a raíz de un desliz histórico del entonces jefe del gobierno español, el Sr. Aznar, aireado por la prensa (Pagès, 1998):

Es evidente que el Sr. José Mạ Aznar, actual presidente del gobierno español, no habría aprobado historia si fuese alumno de la actual ESO [Enseñanza Secundaria Obligatoria] y si se aplicasen para valorar sus conocimientos los criterios que quiere aplicar la Sra. Ministra de Educación de su gobierno, Esperanza Aguirre para evaluar el conocimiento histórico del alumnado de nuestro país. ¿Cómo se puede decir públicamente que el rey Fernando VII conspiró contra su padre a principios del siglo XVIII o que Godoy era el Príncipe de Godoy? Menos mal que el Sr. Aznar hace ya tiempo que estudió historia -en un colegio privado, por cierto- y que el Sr. Kolh, jefe del gobierno alemán ante el que hizo esta afirmación, no sabe mucha historia de España. De todas maneras, si el Sr. Aznar fuese hoy estudiante de primaria, secundaria o bachillerato, encontraría muy pocos profesores que lo suspendieran por este error, a no ser que tuviera por profesora a la Sra. Ministra de Educación o a alguno de los expertos que la asesoraron en la elaboración de un anteproyecto de contra-reforma de la historia que tanta polvareda levantó hace unos meses (...) (Pagès, 1998, p. 2).

Debates como estos mantuvieron vivo mi interés por seguir pensando en cómo debía enseñarse la temporalidad y, en particular, las relaciones entre el pasado, el presente y el futuro. En 1999 publiqué tres trabajos (Pagès y Santisteban, 1999; Pagès, 1999a y Pagès, 1999b).

En uno de ellos presentaba un estado de la investigación sobre la enseñanza y el aprendizaje del tiempo histórico que me permitió seguir argumentando la 
necesidad tanto de profundizar en la investigación como de presentar alternativas a la enseñanza de la historia predominante en España y en la inmensa mayoría de países del mundo (Pagès, 1999a). Revisé la investigación realizada en España y en algunos países de nuestro entorno sobre las concepciones y las prácticas del profesorado, las investigaciones sobre los conocimientos del alumnado de enseñanza primaria y secundaria del tiempo histórico y las investigaciones de la profesora Nicole Lautier (1997a y 1997b) sobre la enseñanza de la historia y del tiempo histórico. Los resultados de las investigaciones analizadas, con excepción de las de Lautier, presentaban un panorama muy triste. El tiempo histórico se identificaba básicamente con la cronología y la periodización, se presentaba como una realidad objetiva, lineal, que existe al margen de los hechos históricos. El profesorado otorgaba mucha importancia a la cronología, pero el alumnado no conseguía aprenderla, conseguía identificar los cambios, pero no los ubicaba cronológicamente. El aprendizaje de la historia que se derivaba de estos resultados puede considerarse memorístico y repetitivo. El pasado no se relacionaba con el presente y mucho menos con el futuro.

Por esta razón, con Santisteban presentamos una nueva propuesta para la enseñanza de la temporalidad en la que destacábamos las aportaciones realizadas a los estudios del futuro desde el mundo de las creencias (la escatología y la apocalíptica), desde las ideologías con la producción de utopías y finalmente desde la prospectiva. Además, presentamos un mapa conceptual sobre dominio y gestión del tiempo como conocimiento y como poder organizado en tres ejes: clasificación/ jerarquización de los hechos históricos, medida del tiempo y control y poder sobre el tiempo. Este último eje contiene tres variables: distribución del tiempo, reestructuración del tiempo y construcción del futuro. En relación con esta última variable afirmábamos:

Se trata de una enseñanza en la cual el alumnado reflexiona sobre los futuros posibles, probables o deseables (Hicks, 1994). Es un aprendizaje que se basa en la formación del pensamiento crítico-creativo, en una educación para la responsabilidad y para la intervención social. La clave de esta enseñanza es transmitir una imagen positiva del futuro, como una parte de nuestra temporalidad que está por construir, que se materializará a partir de nuestra propia acción (Hicks/Slaghter, 1998). El conocimiento histórico y social, entonces, encuentra su significado y su funcionalidad más importante (Pagès/Santisteban, 1999, p. 206).

También escribí un pequeño manifiesto reivindicando la necesidad de relacionar pasado y presente (Pagès, 1999b): «la enseñanza de la historia preocupa, en todo el mundo, a quienes seguimos creyendo en su valor educativo, en la necesidad de formar a las jóvenes generaciones para que, ubicándose en su mundo, sean los auténticos protagonistas de la construcción del futuro». "Los conocimientos históricos (...) son también unos conocimientos para situarse en el presente y 
poder prever como las decisiones que se toman en él pueden prefigurar el futuro. Permiten a las personas proyectarse hacia lo que ha de venir, hacia lo que puede ser» (pp. 10-11). Volví con posterioridad a este tema al desarrollar, en un artículo, las ventajas para el aprendizaje de la comparación histórica (Pagès, 2006).

En mi opinión (Pagès, 1999b), era claro a finales del siglo xx el camino que debíamos seguir:

la nueva sociedad de la información requiere personas con la cabeza bien ordenada más que personas con la cabeza muy llena, pero mal organizada. Requiere personas que sepan utilizar las nuevas tecnologías de la información, más que personas que sean utilizadas por quienes manejan y manipulan la información. Un buen aprendizaje de la historia no solo ha de permitir saber cosas del pasado, sino también ha de permitir a la ciudadanía saber cómo el pasado es y puede ser utilizado contra la libertad de pensamiento y de acción.

La larga sombra del pasado sobre el presente puede ser libertadora o alienadora, conservadora o transformadora, estar al servicio de la democracia y de la justicia social o contra ellas. La historia escolar no es, no ha sido nunca, un producto intelectual neutral. Enseñar historia es comprometerse con una determinada visión del mundo y del futuro. Aprender historia es asumir protagonismo en la construcción responsable y solidaria del futuro y de la democracia en todo el mundo. $Y$ esto es lo que parece que no están dispuestas a tolerar las derechas [hoy diría los mercados] en ningún lugar de nuestra pequeña aldea (p. 11).

¿Han cambiado las cosas en el siglo xxI? No mucho. Tal vez se ha ido tomando consciencia por parte del profesorado de la necesidad de repensar la enseñanza de la historia al margen de los currículos y de las orientaciones oficiales. Se ha visto la necesidad de relacionar más directamente el pasado con el presente y el futuro ha ido abriéndose, con lentitud, un lugar en la enseñanza de la historia y de las ciencias sociales. Por otro lado, ha empezado a ser un lugar común la relación entre la enseñanza de la historia y la formación de la ciudadanía y, en consecuencia, la relación entre pasado y presente y en menor medida, entre ambos y el futuro (Pagès, 2003).

Mi preocupación por esta temática se ha mantenido y solo, o con Santisteban, he ido reflexionado y generando propuestas para una enseñanza de la historia diferente y mucho más centrada en la relación pasado-presente y en el futuro.

Comprender las situaciones cotidianas desde el conocimiento histórico enseñado en la escuela supone reconsiderar el papel de la historia del presente y el papel del futuro en la enseñanza y el aprendizaje del tiempo histórico y de la historia.

La historia del presente ha tenido, como la cronología, mala prensa y muchos detractores (diferentes de los que defendían la cronología). Entre los argumentos más falaces que se han utilizado para evitar al profesorado entrar en "cuestiones» polémicas, en tiempos en los que las vivencias y el recuerdo -la memoria histórica- 
están aún presentes en sus protagonistas, se ha recurrido a reivindicar la distancia necesaria entre el hecho estudiado y quien lo estudia como requisito fundamental de la historia, de la «objetividad» histórica (parece que quienes defienden esta postura consideran que estudiar el presente ha de ser cosas de los periodistas y no de los historiadores). Ciertamente, esta crítica no ha cuajado en la historiografía pero sí que ha tenido defensores en la enseñanza. Aún hoy la historia del siglo Xx sigue siendo la gran desconocida para muchos jóvenes al finalizar su período de escolarización obligatoria como han puesto de manifiesto algunas investigaciones recientes.

Frente a esta situación cada vez son más las propuestas que reivindican la enseñanza del presente y, en concreto, del siglo xx. Sin lugar a dudas, toda la historia es básica para ubicarnos en nuestro mundo e intentar comprenderlo, pero el siglo Xx es más básico que la romanización, por ejemplo. Sin conocer las catástrofes bélicas del siglo pasado, el fascismo y el comunismo, la guerra fría, el Holocausto,... no entenderíamos nada de nada. En cambio, si no sabemos las guerras púnicas, o el siglo de Pericles ignoraremos cosas básicas de nuestro acervo cultural pero, sin duda, esta ignorancia no nos impedirá comprender las causas y las raíces de los problemas actuales.

(...) ¿Y qué pasa con la enseñanza del futuro?, ¿puede la enseñanza de la historia, del pasado, enseñar a construir el futuro? En relación con el futuro y su enseñanza han aparecido en los últimos años reflexiones y propuestas muy valiosas. Personalmente he creído, y creo, que ha sido una categoría infravalorada en la enseñanza de la historia y de las ciencias sociales y que era, y sigue siendo, necesario reivindicar e introducir en las prácticas de enseñanza para posibilitar la formación de la conciencia histórica de niños y jóvenes (Pagès, 2004a, pp. 48 y 50).

Por ello, en la propuesta que realizamos con Santisteban para la enseñanza de la historia en la educación primaria (Santisteban y Pagès, 2006) insistíamos en esta necesaria relación y la ilustrábamos con numerosos ejemplos que concretaban nuestras ideas:

La finalidad fundamental de la enseñanza de la historia en la escuela primaria consiste en ayudar a los alumnos y alumnas a construir su propio conocimiento de la realidad social. La enseñanza histórica ha de fomentar una educación basada en la formación de unos jóvenes ciudadanos reflexivos, críticos, solidarios. Unos niños y unas niñas que han de ser preparados para poder reflexionar y tomar decisiones sobre situaciones personales y sociales del entorno inmediato y del alejado, en el presente y en el futuro (Santisteban y Pagès, 2006, pp. 468-134).

Presentábamos diferentes propuestas de secuencia de los contenidos históricos en la enseñanza primaria (la francesa, la escocesa y la finlandesa) y proponíamos actividades de diferente naturaleza en las que, siguiendo el enfoque temático o de líneas de desarrollo, planteábamos la relación pasado-presente y futuro de manera explícita (la evolución del vestido, de la vivienda o de la escritura, por ejemplo). Algunas de estas ideas y de estas actividades vuelven a estar presentes en un trabajo más reciente (Pagès y Santisteban, 2010) dirigido también a la enseñanza 
primaria donde, de nuevo, insistimos en la importancia de enseñar el futuro como un elemento fundamental de la formación democrática de la ciudadanía.

En los últimos trabajos hemos incorporado al discurso de la relación pasado, presente y futuro ideas procedentes de las aportaciones de la consciencia histórica y de la memoria histórica. Todas ellas ayudan a argumentar la necesidad de una formación democrática de la ciudadanía y dentro de ella del papel de la enseñanza del futuro:

La participación democrática reclama una visión del futuro como una realidad que se está construyendo, que se puede cambiar a partir de nuestra acción social. De la misma manera que reconstruimos el pasado o describimos el presente, también podemos construir el futuro. El desarrollo de las capacidades para la acción social requiere el convencimiento que podemos modificar la realidad social. (...) La clave (...) es hacer reflexionar al alumnado sobre qué futuro desea y cómo debe conseguirse, sobre su futuro personal, sobre su participación en la sociedad, sobre la conservación del medio ambiente, sobre la construcción de la democracia en su ámbito de actuación. De hecho, cualquier temática tratada desde la enseñanza de la historia o desde cualquier ciencia social, tiene una perspectiva de evolución en el futuro, ya sea el estudio de la población, de la ciudad, de la política, de la economía, de la guerra o del patrimonio. Parece imprescindible entonces pedir a nuestro alumnado que aprenda a interpretar el futuro, como aprende a interpretar el pasado o el presente (Pagès y Santisteban, 2008, pp. 106-107).

Las experiencias que hemos desarrollado y las investigaciones que hemos realizado, nos hacen creer que

la historia puede aportar a esta conciencia ciudadana los conocimientos, los valores y las habilidades mentales necesarias para que nuestros jóvenes sepan que su futuro será el resultado de lo que ha existido, de lo que estamos haciendo y de lo que harán hombres y mujeres en un contexto cada vez más globalizador y en el que hará falta saber en cada momento cómo decisiones que se toman a muchos kilómetros de donde residimos pueden llegar a afectarnos con mucha mayor fuerza que decisiones que se toman al lado de casa. $Y$, al revés, como acciones que tomamos cerca de nuestra casa pueden tener un peso decisivo para frenar decisiones que están sucediendo a miles de kilómetros de donde vivimos (Pagès, 2007, p. 214).

\section{Y también nos hacen creer que}

en el presente -en el futuro del pasado y en el pasado del futuro- el alumnado ha de poder comprobar los resultados de determinados acontecimientos históricos, como determinados cambios o continuidades se han materializado en nuestro paisaje, en nuestra vida. Pero, además, el uso del presente puede hacer aflorar las diversas experiencias de cambio que han construido los y las alumnas a partir de sus propias 
experiencias. En una sociedad cada vez más multicultural como la nuestra [me refiero a la catalana y a la española], hacer aflorar las experiencias de cambio vividas por chicos y chicas de diferente procedencia (...) puede permitir una mejor comprensión de los otros y puede facilitar que, a partir de pasados diferentes, los niños y las niñas, los chicos y las chicas puedan caminar juntos en la construcción del futuro. Sin duda, una perspectiva plural del pasado, y de su temporalidad, debería ayudar al alumnado a dibujar futuros posibles basados en la convivencia armónica de historias y temporalidades plurales (Pagès, 2009, p. 8).

He seguido reflexionando sobre los problemas de la enseñanza de la temporalidad hasta prácticamente la fecha. He participado en distintos proyectos de investigación y he fomentado la realización de tesis doctorales sobre la temática (por ejemplo, Muñoz y Pagès, 2012; Llusà y Pagès, 2013). Parece que la tarea es más ardua de lo que pensé cuando inicié mis trabajos sobre la enseñanza de la historia y la formación de la temporalidad. Sigo creyendo, sin embargo, que la enseñanza de la historia y, dentro de ella, la comprensión del presente y la prospectiva del futuro, son necesarias e inevitables si creemos en el valor educativo de la historia y en su potencial para la transformación social: «Valorar la utilidad social de la historia facilita al alumnado la toma de decisiones sobre su futuro personal y social» (Pagès y Llusà, 2016, p. 31).

Estas reflexiones, estas ideas, estos planteamientos se han ido materializando en distintas propuestas curriculares y en diversos materiales con una doble intención. Por un lado, intentar que el currículum y los programas que de él se derivan estén en consonancia con los resultados de las investigaciones históricas y didácticas. Por el otro, facilitar al profesorado que lo deseé innovar su práctica.

\subsection{Proyectos y materiales curriculares}

Desde prácticamente mis primeros años en la enseñanza y en la didáctica he procurado que las propuestas y los materiales didácticos que he elaborado, solo o con otras personas, presenten un enfoque problemático de la enseñanza de la historia y un enfoque en que la relación pasado-presente y futuro se muestre de la manera más explícita y clara posible. El pasado es presentado como una construcción, como una posibilidad de hacer aquello que queramos hacer a partir de indagar sobre la naturaleza de un problema o de una situación problemática más o menos conflictiva. Dependiendo de la naturaleza del contenido la concreción puede ser de una manera o de otra. En cualquier caso, el contenido siempre obedece a una situación sentida desde el presente como problemática y que se proyecta hacia el futuro.

Presentaré, en primer lugar, aquellos proyectos curriculares en los que he participado para concluir este apartado con algunas unidades didácticas realizadas individual o colectivamente. 


\section{i. La propuesta curricular de Ciencias Sociales de «Rosa Sensat» (1981)}

A raíz de la última reforma educativa de la dictadura franquista (Ley General de Educación de 1970), el Grupo de Ciencias Sociales de Segunda Etapa de EGB del movimiento de renovación pedagógico «Rosa Sensat» de Catalunya, del que formaba parte, aprovechó la situación política del tardofranquismo y de la transición y apostó por elaborar dos propuestas curriculares alternativas a la propuesta oficial. Me centraré en la segunda (Grup de Ciències Socials de "Rosa Sensat», 1981). Esta propuesta se divulgó a través de las escuelas de verano y de los cursos de invierno y se publicó en 1981. Para los cursos 7. y 8.으 de Educación General Básica, los dos últimos cursos de la escuela obligatoria en aquellos años, se diseñó una propuesta interdisciplinar, geo-histórica, con la clara intención de relacionar pasado y presente y abrir puertas al futuro. Esta programación se inspiró fundamentalmente en los principios desarrollados por Nidelcoff (1971) y en las aportaciones de la histórica diacrónica o temática (Marbeau, L. et al., 1974 y Hodeige, 1981).

Nidelcoff (1971) propuso un modelo del currículo de ciencias sociales organizado en torno a cuatro variables, dos espaciales y dos temporales: los hombres de nuestro lugar, los hombres de nuestro tiempo, los hombres de otros lugares y los hombres de otros tiempos. Apoyó su propuesta en ideas como las siguientes:

Conocer cómo viven, qué problemas enfrentan y a qué aspiran los hombres de nuestro tiempo, en suma: tomar conciencia de los problemas de nuestra época, comenzar a asumir un compromiso frente a ellos, esto tendría que ser el aporte principal que la escuela brindase a los chicos (p. 27).

Esperamos que, a través del aprendizaje de la HISTORIA, nuestros alumnos sean capaces de COMPRENDER EL PRESENTE: -viendo a nuestro mundo como resultado de un largo proceso, -captando en el presente las derivaciones de los hechos del pasado, $-y$, sobre todo, despertando la actitud de ver las raíces históricas de los fenómenos contemporáneos y las perspectivas futuras de nuestro presente (p. 60).

Nidelcoff apostaba por una enseñanza de la historia que habituase a los alumnos a comparar «períodos históricos entre sí, el pasado con el presente, viendo los cambios que se han operado: en la forma de organizar la sociedad, la forma de trabajar, la vivienda, la alimentación, las costumbres, e, incluso, en la gente misma: en su manera de ver la realidad, en sus valores, en suma, en su mentalidad» ( $p$. 63). Para esta autora, "La percepción del cambio es también liberadora de una visión pesimista del mundo actual y del futuro. Los chicos descubrirán avances en las condiciones de vida del hombre actual y también en sus sentimientos de cara a la humanidad (...)» (p. 64). 
Por su parte la historia diacrónica o temática apuesta claramente por la comparación, por la analogía. Hodeige (1981) destacaba las siguientes ventajas educativas de la historia diacrónica, o temática:

- ofrece una visión panorámica de la historia permitiendo al alumnado fijar las nociones de evolución cronológica y espacial,

- facilita la comprensión de la cronología y de las duraciones, y del cambio y de la continuidad,

- $\quad$ sitúa en el centro de sus preocupaciones la relación pasado y presente, abriendo las puertas al futuro,

- favorece las comparaciones con otros grupos humanos en el pasado y permite situar nuestra historia en relación con la historia de los otros.

La propuesta realizada por el Grup de Ciències Socials de "Rosa Sensat» se concretó en torno a ocho ejes temáticos: tres para séptimo (la agricultura, la industria y el comercio) y cinco para octavo de Educación General Básica (la demografía, la ciudad, la industrialización, la sociedad industrial y la organización política contemporánea). La intención era estudiar el pasado y el presente abriendo puertas al futuro. Por ejemplo:

\section{7. curso (12-13)}

8.ำ (13-14)

La agricultura.

- Orígenes.

- La situación de la agricultura desde los íberos a los siglos XVI-XVII.

- Cambios en la agricultura catalana en el siglo XVIII.

- Condiciones de vida en el campo a través del tiempo.

- La agricultura en Catalunya y en el mundo hoy.

Esta propuesta formó parte de la programación experimental del ciclo superior de EGB (11-14) que, ya en democracia, realizó el gobierno catalán en los años ochenta. La aprobación de la LOGSE, la apuesta por la extensión de la enseñanza obligatoria hasta los 16 años, la creación de una nueva etapa educativa (la enseñanza secundaria obligatoria, ESO, 12-16 años) y la apuesta por un currículo más abierto dieron al traste con este enfoque que solo mantuvieron algunos centros y algunos profesores a título individual. 
ii. El enfoque de la historia en el área de Conocimiento del Medio de educación primaria (1995)

Algunas de las ideas desarrolladas en el programa de "Rosa Sensat» fueron recuperadas en la propuesta curricular para el área de Conocimiento del Medio [social y natural] de educación primaria (6-12) de una editorial española cuyos libros de texto tuve la ocasión de coordinar (Pagès (coord.), 1995). Concretamente, el enfoque que se dio a la historia y a la enseñanza de la temporalidad tuvo desde el primer curso hasta el último una clara intención de relacionar pasado, presente y futuro. El programa de 6. curso, el último, estaba dedicado al tiempo, estaba formado por 15 lecciones organizadas en tres secciones: 1) El tiempo y la evolución (1 a 5), 2) Ventanas al tiempo (6-8), y 3) La historia y la cultura (9-15). Se combinó una enseñanza conceptual de la temporalidad, y un enfoque sincrónico, cronológico, y diacrónico de la historia. Este es el desarrollo de algunas lecciones

1. El tiempo.

9. Las etapas de la historia.

13. La historia de la escritura.

\author{
¿Tiempo o tiempos? \\ El tiempo y el cambio. \\ La medida del tiempo. \\ La historia de la tierra y de la humanidad.
}

Presente, pasado, futuro.

Las etapas de la historia.

Testimonios del pasado: las fuentes de la historia.

La comunicación humana.

El lenguaje de los signos.

Escribiendo con imágenes.

La cuna de la escritura.

Los orígenes de nuestra escritura.

La biblioteca de los monasterios.

Medievales.

De la escritura manual a la escritura impresa.

La prensa periódica: su historia.

El diseño gráfico nos invade.

El escaso éxito editorial de este enfoque llevó a la empresa a sustituirlo por un enfoque clásico de la enseñanza de la historia del que desapareció la relación pasado, presente y futuro. 


\section{iii. El currículo de Ciencias Sociales, Geografía e Historia para la Enseñanza} Secundaria Obligatoria de la Generalitat de Catalunya

Tuve la ocasión, junto con otras personas, de participar en la elaboración del currículo de Ciencias sociales, geografía e historia del Gobierno tripartito catalán que se encargó que concretar en Catalunya la reforma curricular impulsada por el Gobierno de Rodríguez Zapatero. Tuve la ocasión de participar en un intento de plasmar a nivel institucional algunas de las ideas que había estado trabajando. Esto fue posible en la introducción, pero no lo fue tanto en el desarrollo de los contenidos de cada curso, que en buena parte venían prescritos por el decreto de contenidos mínimos aprobado por el gobierno español de obligado cumplimiento por todas y cada una de las comunidades autónomas.

En la introducción del área de Ciencias sociales, geografía e historia de la Enseñanza secundaria obligatoria (ESO) explicitamos las aportaciones de la historia y de la geografía a la formación del alumnado. Entre ellas, las relaciones pasado, presente y futuro.

Las sociedades occidentales confían en la enseñanza de la historia y en la formación de una ciudadanía informada y crítica para participar en la vida democrática de sus países. También confían que la enseñanza de la historia permitirá a las jóvenes generaciones formar su pensamiento, su conciencia histórica y sus identidades. Además, la enseñanza de la historia ha de posibilitar que las jóvenes generaciones preserven para el futuro la memoria histórica del pasado y el patrimonio cultural. (...) El desarrollo de la conciencia histórica ha de permitir al alumnado construir su conciencia temporal, es decir, ha de poder construir su historicidad como consecuencia de las interrelaciones entre el pasado, el presente y el futuro. Ha de ser capaz de percibir la presencia del pasado en el presente y poder proyectarse del presente hacia el futuro. (...) El conocimiento histórico es clave para que el alumnado aprenda a participar en la vida democrática de un país, a tomar partido ante los problemas del mundo, a participar en la transformación y la mejora de la propia sociedad y del mundo y a seguir aprendiendo para participar en el futuro" (Generalitat de Catalunya, 2010, pp. 112-113).

Además, en las orientaciones metodológicas pusimos especial énfasis en relacionar el pasado, el presente y el futuro y en la comparación.

Sin embargo, en la propuesta curricular de cada curso no hay apenas concreciones que permitan relacionar y comparar el pasado con el presente y mucho menos trabajar el futuro. Solamente en el cuarto y último curso de la Enseñanza secundaria obligatoria el presente y el futuro están realmente presentes en el currículo escolar, aunque este último no lo está de manera demasiado explícita. La razón es clara: el último curso de la enseñanza secundaria obligatoria estaba centrado en la historia reciente, en la contemporaneidad y en el propio presente. En 1.ㅇ y 2.으 
prácticamente no se hacía mención ni al presente ni al futuro, y cuando se hacía era, por un lado, de manera marginal, relacionada con las fuentes como recursos de enseñanza, o con la utilización política del pasado (la antigüedad, y la continuidad de las instituciones de gobierno). En segundo y en tercero se planteaban tres contenidos de manera temática o diacrónica. En ellos se presenta la evolución de un aspecto social (la población, las relaciones entre tecnología, organización social y producción de bienes y la organización política y territorial) a lo largo de la historia y hasta el presente.

El desarrollo de estos contenidos y del enfoque que quisimos dar a la enseñanza de la historia en la introducción dependió de las editoriales de los libros de texto, de los proyectos curriculares de cada centro y de su profesorado.

\section{iv. La propuesta curricular del Govern de Andorra}

La última propuesta curricular en la que participo es la del Govern d’Andorra. Desde el año 2011 colaboro con Santisteban en la elaboración de la propuesta curricular de Ciencias Sociales para la escuela andorrana (escuela maternal, primera enseñanza, segunda enseñanza y bachillerato). En estos momentos hemos finalizado los programas de Segunda enseñanza ${ }^{4}$ y Bachillerato y estamos trabajando en los de maternal y primera enseñanza.

La finalidad principal de la propuesta Ciencias Sociales de Segunda enseñanza (Sala (coord.), 2018) es «dotar a los alumnos de herramientas sólidas para comprender el mundo en que viven e intervenir de manera constructiva en él» (p. 7). Esta propuesta está organizada en tres grandes competencias que se despliegan a partir de los conceptos clave de las ciencias sociales, entre ellos el concepto continuidad y cambio. La segunda competencia está focalizada en la historia «Interpretar la evolución histórica a partir de los cambios políticos, económicos, culturales o sociales, a diversas escales temporales y espaciales». Se apuesta por combinar el enfoque sincrónico con el diacrónico y se sugiere, en las orientaciones metodológicas de la competencia «desarrollar en el alumnado una conciencia histórica, para relacionar el pasado con el presente y, sobre todo, no olvidar la categoría temporal del futuro que da sentido al estudio de la historia» (p. 10).

Los contenidos -recursos de aprendizaje en la propuesta oficial andorrana- se estructuran en los bloques siguientes: 1 . Distribución de la riqueza y desigualdades sociales, 2. Desarrollo sostenible, 3. Memoria e identidad, 4. Relaciones, conflicto y cambio social, 5. Organización social, y 6 . Un mundo interconectado. En cada bloque se explicitan las intenciones, los conceptos clave que pueden desarrollarse (en todos figura el tiempo y en la mayoría el cambio y la continuidad), los conceptos propios del bloque, y se presentan los hechos y conceptos de cada competencia, los

\footnotetext{
${ }^{4}$ Esta etapa educativa es equivalente, en España, a la Enseñanza secundaria obligatoria (ESO).
} 
procedimientos y las actitudes y valores secuenciados en dos ciclos (1. ${ }^{\text {er }}$ ciclo -1 er $^{\text {er }}$ 2. curso- y 2. ciclo -3.. y $4.9-$ ). Y se finaliza con unas orientaciones didácticas de cada bloque. El último apartado está dedicado a los criterios de evaluación y a las expectativas de final de ciclo.

El presente y el futuro aparecen en prácticamente todos los bloques. Así, y a manera de ejemplo, en el procedimiento Tiempo del bloque 1, para el segundo ciclo, se propone desarrollar una «prospectiva sobre el futuro de la producción económica, los derechos económicos de la ciudadanía, el consumo y la sostenibilidad, haciendo servir el conocimiento acumulado del pasado y la experiencia del presente» (p. 17). En las orientaciones didácticas del Bloque 2 se afirma que el alumnado «Ha de comprender que el futuro está por construir y que se pueden revertir determinadas tendencias negativas económicas o productivas» (p. 21). Entre las intenciones del Bloque 3 se afirma que el alumnado de esta etapa educativa ha de desarrollar «su conciencia histórica, es decir, que construya su historicidad y relacione pasado-presente y futuro (la memoria y la temporalidad histórica)» y que "tome conciencia de la importancia de preservar, para las futuras generaciones, el patrimonio cultural, artístico e histórico del conjunto de la humanidad» (p. 22). Entre los conceptos y hechos propuestos en este bloque figuran, por ejemplo, «Historias y memorias del siglo Xx: silencios y conflictos», "La ciudadanía del siglo XXI: la idea colectiva de un mundo global» 0 «El patrimonio cultural andorrano. Su estado de conservación. Medidas para su conservación» (p. 23). Y así sucesivamente.

Creo que esta propuesta establece un buen equilibrio entre las intenciones y su desarrollo. Sin embargo, dado su carácter abierto, dependerá en última instancia del trabajo de los y las docentes para concretar cada uno de los conceptos, hechos, procedimientos, actitudes y valores de los dos ciclos y buscar los ejemplos más pertinentes para la relación pasado-presente y su proyección hacia el futuro. Y lo mismo sucede con la propuesta de Historia de Bachillerato (Àrea d'Ordenament Curricular, 2018). En la introducción se explica con total claridad que "La finalidad de la enseñanza de la historia en el bachillerato es formar el pensamiento y la conciencia histórica del alumnado a fin de que relacione los problemas sociales relevantes de su mundo con sus antecedentes y piense alternativas de futuro, emita juicios razonados, valore los cambios (...)» (p. 1). La temática se centra en el estudio de la contemporaneidad y de sus antecedentes, por lo que tanto el presente como el futuro figuran en lugares destacados. Está organizada en seis bloques (1. Cambios históricos y continuidades. Los antecedentes, 2. La evolución del sistema económico, 3. Los derechos y los deberes, 4. Ideas, artes y cultura, 5. Poder, conflicto y convivencia y 6 . Otras culturas). La organización de esta propuesta tiene los mismos componentes que la de la segunda enseñanza con la excepción de que no aparecen de manera explícita los conceptos clave.

En la concreción de los criterios de evaluación de una de las dos competencias de esta propuesta se afirma, en relación con el sentido crítico que 
Los relatos históricos se consideran la evidencia más clara del desarrollo del pensamiento histórico y social del alumnado, ya que ponen de relieve su competencia para interpretar, valorar y comunicar su propia historia desde el presente y proyectarla hacia el futuro. Son un ejemplo de construcción de su historicidad y, por tanto, han de ser útiles para comprender el presente. Han de ser, también, un ejemplo de su competencia para transferirlos a situaciones nuevas y a cuestiones socialmente vives del presente y del futuro (p. 26).

\section{v. Estudiar conflictos en el pasado, el presente y el futuro}

La búsqueda de alternativas a la enseñanza tradicional de la historia, y al establecimiento de relaciones entre el pasado, el presente y el futuro me condujo a plantear una unidad didáctica basada en el estudio de dos conflictos en sociedades rurales (Pagès, 1997b). Justifique este enfoque desde distintas perspectivas, poniendo el énfasis en el papel de la comparación en la enseñanza de la historia (Pagès, 2006).

La unidad didáctica estaba focalizada en dos conflictos en sociedades rurales, dos conflictos muy alejados en el tiempo y en el espacio: el conflicto remensa ocurrido en Catalunya en el siglo XV y el conflicto de Chiapas acaecido en 1994 (Pagès, 1997b). Las razones de esta comparación las expuse en la presentación del tema:

Los conflictos, y en concreto las guerras, han constituido uno de los ejes vertebradores del contenido de la historia escolar. Y, tal vez, uno de sus más poderosos elementos de socialización. El conocimiento de los principales conflictos sociales y de las principales guerras que se han producido a lo largo de la historia se han presentado muchas veces como un fin en sí mismas. A través de una información básicamente factual, en la que predominaba el estudio de las batallas, de sus protagonistas, del armamento utilizado, etc... se ofrecía al alumnado una de las posibles visiones del conflicto con el fin de que pudiera distinguir con relativa facilidad los «buenos» de los «malos». El maniqueísmo, el simplismo y el partidismo con que han sido tratados los conflictos y las guerras en el currículo escolar y en muchos libros de texto ha sido una consecuencia del predominio de la racionalidad positivista en la enseñanza de las ciencias sociales. Como casi todo el conocimiento social, y en especial el conocimiento histórico, los conflictos y las guerras se han presentado como un conocimiento objetivo, como algo natural e inevitable» (Pagès, 1997b, p. 417).

En esta unidad didáctica confluían las aportaciones procedentes de tres campos: a) la educación para la paz y el estudio de conflictos, b) el conflicto como concepto clave en el currículo de ciencias sociales y c) el conflicto como constructo curricular y como problema objeto de estudio de las ciencias sociales y de la historia. 
La unidad didáctica está organizada en cuatro secuencias: una presentación del tema en la que se trata de indagar los conocimientos que el alumnado tiene del conflicto, el conflicto remensa, el conflicto de Chiapas y, para concluir, la comparación entre los dos conflictos y el análisis y valoración de otros. El estudio de cada uno de los conflictos se realizaba siguiendo las siguientes pautas: la ubicación territorial y temporal del conflicto, la cronología del conflicto, el contexto socioeconómico y político del conflicto, las reivindicaciones que dieron origen al conflicto y sus causas y las interpretaciones del conflicto. Enseñar al alumnado a interpretar los conflictos me pareció uno de los aprendizajes más importantes, tanto por sus posibilidades de aplicación a otros conflictos del pasado, como a los del presente y a los del futuro. En la última secuencia se presentaban las pautas para el análisis y valoración de cualquier conflicto que estallara en el futuro siguiendo las mismas variables que se trabajan en cada uno de los dos conflictos objeto de estudio.

\section{vi. La ciudad del futuro}

El Instituto de Educación de la municipalidad de Barcelona realiza desde hace ya unos cuantos años un programa de formación democrática de los adolescentes (de 12 a 18 años) conocido con el nombre de Audiencia Pública. Es un programa que se ofrece a los centros educativos de la ciudad y que tiene como finalidad enseñar a los jóvenes a participar en la vida política de la ciudad. Cada curso se elige un tema diferente que es trabajado por el alumnado de cada centro, los resultados se ponen en común por zonas geográficas y finalmente se acaba presentando a la máxima autoridad municipal los resultados alcanzados y las reivindicaciones de los jóvenes ${ }^{5}$. He participado en varias Audiencias Públicas como asesor. Fui el responsable de asesorar y elaborar los materiales de la VIII Audiencia Pública dedicada a su ciudad, al futuro de su ciudad. La Audiencia estaba centrada en la pregunta: ¿Cómo queremos la Barcelona del futuro? Esta pregunta iba acompañada del siguiente subtítulo: De la preservación del patrimonio al urbanismo de mañana. Su finalidad era la formación democrática de los muchachos y de las muchachas para que aprendan a actuar con eficacia en la planificación, la construcción y la conservación de Barcelona, se identifiquen con ella y sean capaces de imaginar y traducir en acciones realistas escenarios de futuro.

El material que preparé (Pagès, 2004b) estaba organizado en tres secciones: 1) Barcelona es Barcelona: ¿Dónde estamos?, 2) Barcelona: ¿De dónde venimos? Del pasado al presente. Grandes etapas de la evolución de Barcelona, y 3) Barcelona:

${ }^{5}$ Durante el curso 2009-2010 con Santisteban asesoramos al profesorado y elaboramos el material de la XV Audiencia Pública dedicada a la mejora del paisaje urbano: Barcelona mejora su paisaje. Medidas para la protección y la calidad del paisaje urbano. 
¿Hacia dónde vamos? Presente y futuro. Esta última sección estaba organizada de la siguiente manera:

1.1. ¿Estás preparado/ada para intervenir en la construcción del futuro de Barcelona?

1.2. ¿Qué está pasando enBarcelona? ¿Qué está pasando en mi barrio? La ciudad se transforma.

1.3. La participación de los ciudadanos y de las ciudadanas en la construcción de Barcelona.

1.4. ¿Cómo se planifica, cómo se programa la ciudad del futuro? El futuro de Barcelona y el futuro de mi barrio.

1.5. ¿Qué Barcelona quiero? ¿Qué Barcelona queremos? Un manifiesto por el futuro de la ciudad.

1.5.1. Cómo me gustaría que fuera Barcelona si fuese...

1.5.2. ¿Cómo se debe participar para construir la Barcelona del futuro? Yo pienso que... La clase piensa que...

1.5.3. ¿Qué podemos hacer para mejorar nuestro barrio? Realización de un proyecto urbanístico

Las actividades de esta última sección se centraron en el presente y en sus repercusiones de futuro. Se trataba de que el alumnado comprobara que el futuro es un tiempo por construir y que del presente no se deriva únicamente un futuro, sino que son posibles futuros diferentes. El futuro que predominará será el resultado de la correlación de fuerzas e intereses que se impongan, de manera democrática, en relación con proyectos concretos actuales. Por eso, en una sociedad democrática no es comprensible una imposición autoritaria de los intereses de una parte sobre los del resto, sino que debe intentar buscarse el consenso entre los diferentes protagonistas u obtener el apoyo de la mayoría de ciudadanos y ciudadanas.

La participación democrática en la construcción del futuro de la ciudad tiene como premisas la necesidad de estar informado, de actuar a distintos niveles, de colaborar, de denunciar, de proponer... Es importante que la ciudadanía conozca desde la escuela que el pasado tuvo un presente que se proyectó hacia el futuro, de la misma forma que el presente actual ha sido futuro y será pasado y el futuro será, primero, presente $y$, después, pasado. ¿Cuántos futuros existen o pueden existir? ¿Cómo queremos que sea el futuro de la ciudad y de nuestro barrio? ¿Qué debemos hacer para lograrlo? Las respuestas a preguntas como estas obligan a la 
formación democrática de la ciudadanía para su participación en la vida y el futuro de la ciudad. Y, además, hacen creibles los conocimientos escolares.

El estudio de la ciudad y, en general, del territorio, permite establecer continuas relaciones entre pasado y presente y elaborar proyectos verosimiles de futuro. Permite, además, estudiar aquellos proyectos que, en un pasado determinado, pugnan por convertirse en proyectos de futuro. Tuve la oportunidad de plasmar algunas de estas ideas y algunas de las preguntas anteriores en unos materiales curriculares destinados a 5. y 6. de primaria (GREDICS, 2011). Estos materiales fueron elaborados a iniciativa de Mapfre y con la colaboración del Consell de Coordinació Pedagògica del Ayuntamiento de Barcelona. Estan destinados tanto a observar el crecimiento de Barcelona desde la Torre Mapfre como a analizar la transformación de una zona fundamental para comprender los origenes de la industrialización y los cambios producidos en la misma a raiz de los Juegos Olímpicos de 1992. También a conocer un edificio como la Torre Mapfre, sus características y sus posibles riesgos ${ }^{6}$. En la introducción de estos materiales se afirmaba:

Las actividades históricas a desarrollar en, y desde, la Torre MAPFRE han de permitir al alumnado de 5. y 6. ubicar su propia historia en el tiempo social y relacionar el pasado con el presente y el futuro, situarse ante los grandes períodos de la historia de Cataluña y España, en especial de los siglos XX y XXI, utilizar todo tipo de informaciones, evidencias y fuentes para construir relatos y narraciones históricas sobre situaciones concretas y, finalmente, valorar proyectos relacionados con la difusión y la conservación del patrimonio local (GREDICS, 2011, p. 5).

\section{vii. Enseñar contenidos históricos controvertidos}

No solo la ciudad permite establecer relaciones entre el pasado, el presente y el futuro. Es posible, y deseable, hacerlo en cualquier tema de historia. Sirvan como ejemplo, dos propuestas que, a iniciativa del Instituto de Educación de Barcelona, elaboré con Casas (Pagès y Casas, 2005) y con Nomen y González (Pagès, Nomen y González, 2010) en torno a las consecuencias de la Guerra Civil, para que los y las jóvenes de enseñanza secundaria conocieran lo que había sucedido con los republicanos y republicanas españoles en los campos de concentración nazis después de la Guerra civil española (1936-1939) y con las mujeres republicanas dentro o fuera

${ }^{6}$ Es una colección de cinco cuadernos de trabajo más uno de presentación bajo el título genérico de Descobrim la Torre Mapfre, descobrim Barcelona. El primer cuaderno está destinado a descubrir Barcelona -Descobrim Barcelona-, el segundo a estudiar la transformación del barrio de Icaria en la Vila Olímpica -Del barri d'Icària a la Vila Olímpica-, el tercero a la propia Torre Mapfre-Descobrim la Torre Mapfre-, el cuarto a la construcción y la actividad en la Torre Mapfre y el quinto a los riesgos de la Torre Mapfre. 
de España tanto en el inicio de la Guerra como en su finalización y a la muerte de Franco.

En el primer caso, es un material pensado para que el alumnado pudiera comprender, a través del testimonio de los republicanos españoles, que el nazismo y el genocidio nazi no fueron un hecho casual, un accidente, una anécdota de la historia, sino el resultado de decisiones tomadas conscientemente por personas, instituciones y gobiernos para legitimar la discriminación étnica, social, política y religiosa, favorecer los prejuicios y el odio y asesinar en masa a millones de personas. Entre sus objetivos destacaría, como ejemplo de la relación pasado, presente y futuro el siguiente:

- aplicar los conocimientos y valores aprendidos a los problemas del mundo actual, denunciar aquellas situaciones en que se aplican métodos nazis y actuar con todos los medios democráticos para intentar evitarlas,

- denunciar el silencio y la indiferencia ante el sufrimiento, la violación de los derechos humanos, la intolerancia, los desequilibrios económicos y cualquier manifestación que atente contra la dignidad humana (p. 10).

Los contenidos se referían al nazismo, a los campos de concentración, a los prisioneros, a la vida y a la muerte en los campos de concentración y al final de la guerra y la liberación de los prisioneros. La propuesta terminaba con un apartado dedicado al genocidio nazi hoy y a otros genocidios donde se preguntaba al alumnado: ¿Puede volver a pasar una catástrofe como la que se vivió durante el nazismo?, ¿Qué hemos de hacer para evitarla?, ¿Qué pasa en el mundo hoy? ¿Se podrían producir nuevos genocidios? Se presentaban ejemplos de situaciones que en 2005 podían provocar, según los medios de comunicación, genocidios y se daban pautas para la acción. Se proponía al alumnado de enseñanza secundaria que, para finalizar, realizara una de las tres actividades siguientes:

a. Cambiar la enseñanza para cambiar el mundo: cambios en la programación, en la que se pedía qué cambios deberían realizarse para que la enseñanza de la historia priorizara el estudio de hechos como el tratado en esta unidad didáctica,

b. Preservar la memoria para el futuro: enseñar a niños y niñas, donde se pedía que preparasen una clase sobre los republicanos en los campos de concentración de unos 30 minutos para enseñar a niños y niñas de 8 a 10 años, e

c. Informar a la comunidad de la pervivencia de ideologías y prácticas nazis: una exposición a favor de la dignidad humana, una actividad destinada a dar a conocer a la comunidad el testimonio de los republicanos y a denunciar la presencia de ideologías y prácticas nazis en la actualidad.

La unidad incluía testimonios orales y escritos de republicanos y republicanas, textos de diferente naturaleza, fotografías, canciones, etc. La comparación entre la 
situación histórica y alguna de las situaciones que se vivían en aquellos momentos condujo a las autoridades municipales a la retirada de este material.

La segunda propuesta-Mujeres del 36 (Dones del 36)- está pensada como homenaje a la asociación de mujeres de distintas ideologías que a la muerte de Franco quisieron dejar testimonio de su actuación durante la Guerra Civil (1936-1939), y después de ella. Pretende hacer visibles a las mujeres en el pasado, pero también en el presente y en el futuro. El material didáctico que elaboramos con Nomen y González (2010) estaba destinado a que el alumnado de la enseñanza secundaria conociera el importante papel que las mujeres republicanas tuvieron en la Guerra Civil española. En primer lugar, presenta el papel de las mujeres en el estallido de la guerra civil con su situación al final, con la derrota de la República (cárceles, exilio, guerra mundial, campos de concentración,...) y con el regreso de la democracia, a la muerte del dictador Franco. También compara el papel de las mujeres republicanas con la represión que para la mujer supuso el franquismo y, finalmente, compara la situación de las mujeres en la República con la situación de las mujeres en Cataluña, España y el mundo hoy.

La intención de esta propuesta es que los chicos y las chicas sitúen y valoren el papel de las mujeres republicanas en el contexto de una guerra y lo comparen con las situaciones vividas con posterioridad. Pero también pretende comparar el papel de estas mujeres con la situación de las mujeres hoy a fin de ayudar a los chicos y a las chicas a comprender el largo proceso seguido por las mujeres para llegar a alcanzar la igualdad con los hombres. Las mujeres republicanas alcanzaron unas cotas de libertad que, en la misma España y en otros países, costó mucho tiempo lograr. La comparación por la que apostamos no pretende esconder que el proceso de igualdad entre hombres y mujeres aún no ha finalizado. Hay muchas situaciones que aún hoy ponen en evidencia que hay muchas mujeres en el mundo discriminadas y sometidas al poder de los hombres. La más importante es, sin duda, la violencia que se ejerce contra ellas tanto en los países democráticos como en los no democráticos donde las mujeres, como los niños y las niñas y las personas mayores suelen ser víctimas de todo tipo de injusticias y de atentados contra su dignidad.

En la presentación de su trabajo, recogimos un texto de la Asociación Les Dones del 36 -Mujeres del 36- donde se afirmaba:

Más allá del pasado manipulado y silenciado, más allá de las vidas ignoradas, más allá del dolor. Las mujeres rompen su silencio... y hablan. Nuestra historia es también la de miles y miles de mujeres anónimas. En este caminar por la vida, hemos sobrevivido a la guerra, al exilio, la dictadura, las cárceles, la lucha antifranquista, la clandestinidad... Estos son nuestros testimonios (Associació «Les dones del 36», 2006, p. 24).

Los testimonios orales, fotográficos, escritos de estas mujeres se presentan organizados en tres apartados: 
1. El 18 de julio de 1936 y el alzamiento militar que incluye su papel como milicianas, su compromiso político y sindical, la vida cotidiana, la imagen de la mujer republicana, los bombardeos y la retaguardia, etc.

2. El 1 de abril de 1939. Las mujeres republicanas al finalizar la Guerra civil y en la España de Franco con la represión y la vida y la muerte en las cárceles franquistas, el exilio y su papel en la Resistencia francesa y en los campos de concentración nazis, y las mujeres franquistas, y

3. El 20 de noviembre de 1975. El inicio del final de la dictadura y las mujeres del 36. Las mujeres hoy en Catalunya, España y el mundo.

La última actividad consiste en analizar los datos de un informe elaborado por la ONG Manos Unidas en 2004 sobre la situación de la mujer en el mundo con datos sobre la pobreza, la violencia, la educación, la salud, el trabajo, y la política. Se pide a los alumnos de enseñanza secundaria que analicen los distintos temas y propongan alternativas realistas para mejorar la situación de la mujer en el mundo. La actual situación de la mujer permite seguir trabajando este tema, comparando el pasado con el presente y pensando alternativas para el futuro.

\section{viii. Construir Europa}

Para concluir este apartado, presentaré el material que elaboré en 2006 para celebrar la conmemoración del vigésimo aniversario de la integración de España en Europa (Pagès 2006). Entre las finalidades de este material figuraba, en primer lugar, «analizar la actual situación de la Unión Europea, las principales etapas de su construcción y sus instituciones» y en último "participar en la elaboración de algún proyecto de futuro para Europa y para la ciudadanía europea» (p. 3). Ambas finalidades reflejaban el título de la unidad: Cataluña y España en Europa ayer, hoy y mañana.

La intención era fomentar la participación de los jóvenes en el proceso de construcción de una Europa democrática, proceso que no solamente no ha concluido y que exige la implicación activa de todos sus ciudadanos y ciudadanas, sino que en la actualidad está en riesgo de paralizarse y aun de destruirse. El material constaba de nueve apartados que empezaban con Una cronología de las etapas de la evolución de la Unión Europea y concluían con una actividad cuyo título era ¿Cómo nos gustaría que fuera la Unión Europea en el futuro inmediato? ¿Y dentro de 10 años? Los otros temas estaban dedicados a la identidad y la ciudadanía europea, las instituciones europeas, los proyectos europeos, la movilidad estudiantil, los derechos y los deberes de los y las europeas, y el análisis de lo que supuso para Cataluña y España la entrada en la Unión Europea. El desarrollo de la actividad, bastante abierta para que el alumnado pudiera escoger el aspecto sobre el que trabajaría, incluía la elaboración de un informe detallando los objetivos del proyecto, su proceso de 
implementación, los medios y las ayudas necesarias y las aportaciones de la UE al proyecto y las del proyecto a la UE. Todo ello en una proyección a 2 años vista, en primer lugar, y a 10 en segundo. En el acto conmemorativo del día de Europa, el 9 de mayo del mismo 2006, algunos centros presentaron los materiales con sus propuestas.

\section{PUNTO FINAL}

Todos estos materiales, todas estas propuestas, todas estas ideas están pensados para facilitar que el alumnado relacione el conocimiento del pasado con su presente y con su futuro. Para que construya su historicidad, su pensamiento y su conciencia histórica. Se sabe que esta relación no es fácil de enseñar y mucho menos de aprender. Existen valiosas investigaciones que ponen de relieve dónde están los problemas. Y que dan pistas sobre cómo deberíamos enseñar y deberían aprender los y las estudiantes. Pero también sobre los déficits que tiene la formación del profesorado al respecto.

Desde el programa de doctorado en Didáctica de las ciencias sociales de la UAB se han realizado tesis doctorales sobre la enseñanza y el aprendizaje de distintos aspectos de la temporalidad y sobre la formación del profesorado para su enseñanza. El futuro ha estado siempre presente. Desde GREDICS se han realizado y se están realizando investigaciones que también ponen el énfasis en lo mismo. En síntesis, disponemos de reflexión suficiente, de materiales y propuestas curriculares y la investigación ofrece resultados esperanzadores, pero la enseñanza de la historia no está en su mejor momento y la relación pasado, presente y futuro sigue siendo insuficiente. ¿Qué más hemos de hacer para qué «la historia que se hace en las escuelas [deje de ser] una espesa historia de museo, que no tiene presente ni futuro (...); útil para aprobar los exámenes pero incapaz de hacer madurar la idea que un joven tiene del mundo" como señalaba Deiana (1997, p. 28) a finales del siglo pasado?

Tal vez sea necesario recurrir de vez en cuando a la historia para, alejándonos de los problemas de su enseñanza, aprender a releer nuestros propios textos desde algunos sabios consejos de quienes no tienen entre sus preocupaciones inmediatas la formación de los niños y de las niñas ni de la juventud. Jenkins (2008), por ejemplo, nos ofrece pistas que merecen ser tenidas en cuenta por quienes deciden qué historia enseñar, quienes la escriben en libros de texto o en otros formatos curriculares, quienes la enseñan y quienes forman a quienes la enseñan.

En su novela 1984, Orwell escribió que quienes controlan el presente controlan el pasado y quienes controlan el pasado controlan el futuro. Probablemente esto también es válido fuera de la ficción. Las personas en el presente necesitan 
antecedentes para situarse en él y para legitimar sus formas de vida actuales y futuras (en realidad los "hechos» del pasado -o cualquier otro hecho- no legitiman nada en absoluto si tenemos en cuenta la distinción entre hecho y valor, aunque lo que aquí nos interesa es que la gente actúa como si lo hicieran). Las personas sienten literalmente la necesidad de enraizar su hoy y su mañana con su ayer. Hace poco que las mujeres, los negros, los grupos regionales, las minorías varias, etc. han comenzado a buscar su ayer (y lo han encontrado dado que el pasado admite innumerables narrativas. En estos pasados se encuentran explicaciones para las vidas presentes y se elaboran programas para el futuro. (...) En este sentido todas las clases o grupos escriben sus autobiografías colectivas. La historia es el modo en que las personas crean, en parte, sus identidades; de manera que la historia es mucho más que una parte del currículo escolar o académico, aunque reconozcamos que lo que se introduce en dicho currículo es de crucial importancia para todas las partes interesadas (p. 24).

Si ideas como las de este autor van acompañadas de la necesaria creatividad para pensar alternativas innovadoras que tengan el futuro como punto de mira, como norte de la enseñanza de la historia, tal vez se consiga que el alumnado valore las aportaciones que el estudio de la historia tiene para su presente y para su futuro. Sin duda, este es el reto más importante de la enseñanza de la historia. Y también lo es, como afirma Innerarity (2009), de la política democrática, ya que de ella depende «la mediación entre la herencia del pasado, las prioridades del presente y los desafíos del futuro» (pp. 15-16).

Aportaciones como estas y relecturas de los clásicos como Dewey, tal vez, facilitarán que los futuros profesores y profesoras de historia puedan conseguir aquello que los profesores de mi generación hemos soñado que podría ofrecer la historia, pero no lo hemos acabado de alcanzar. ¿ंO estamos frente a una utopía? El futuro lo dirá.

En cualquier caso, es evidente que

En el presente y en el pasado, muy cerca y muy lejos de donde habitamos, tenemos ejemplos muy variados para presentar dilemas al alumnado, hacerles pensar y convencerlos de que ellos son los protagonistas de su futuro. Orientar la brújula de la enseñanza de las ciencias sociales [y en particular de la historia] hacia la educación democrática de la ciudadanía y hacia la justicia social es un reto para el profesorado, que supone mirar más hacia el futuro, hacia el tiempo en que serán los auténticos protagonistas del gobierno de la polis. Es el sueño y la esperanza en un mundo mejor, el del amor y la justicia social, que ni los adultos ni los maestros y las maestras hemos sabido construir (Gutiérrez y Pagès, 2018, pp. 50-51). 


\section{REFERENCIAS BIBLIOGRÁFICAS}

Aguirre, E. (1996). Discurso de...en la Real Academia de Historia. Comunidad Escolar, 23 de octubre 1996, p. 3.

Àrea d'Ordenament Curricular. (2018). Programa d'història de batxillerat de l'Escola Andorrana. Ministeri d'Educació i Ensenyament Superior. Govern d'Andorra. <https://www.educacio.ad/images/stories/estudis/Batxillerat/ProgBatx_ Historia.pdf> (consulta enero 2019).

Arthur, J., Davies, I., Wrenn, A., Haydn, T., Kerr, D. (2001). Citizenship through Secondary History. London: Routledge.

Associació «Les Dones del 36». (2006). Les Dones del 36. Un silenci convertit en paraula, 1997-2006. Barcelona: Les Dones del 36.

Audigier, F. (1999). L'éducation civique dans l'enseignement secondaire: quelques repères historiques. IREHG, 7, pp. 11-27.

Bollo de Romay, P. y Benzrihem, L. B. (1963). La historia en la escuela secundaria. Buenos Aires: EUDEBA.

Cousinet, R. (1950). L'enseignement de l'histoire et l'éducation nouvelle. Les Presses d'lle-de-France.

Christian, D. (2005). Mapas del tiempo. Introducción a la «Gran Historia». Barcelona: Crítica.

Deiana, G. (1997). Io penso che la storia ti piace. Proposte didattica della storia nella scuola che si rinnova. Edizioni Unicopli.

Dewey, J. (1985). La significació de la geografía i de la història. En J. Dewey, Democràcia i escola (pp. 148-149). Vic: Eumo.

Evans, R. W. (1996). A critical approach to tecahing United States History. En R. W. Evans, R.W y D. W. Saxe (edd.), Handbook On Teaching Social Issues (pp. 152160) . Washington: National Council for the Social Studies (NCSS) Bulletin 93.

Fontana, J. (1988). L'ensenyament de la història. Actes del Primer Sympòsium sobre l'ensenyament de la història (pp. 21-33). Vic: Eumo. 
Fontana, J. (2013). El futuro es un país extraño. Una reflexión sobre la crisis social de comienzos del siglo XXI. Barcelona. Pasado\&Presente

Generalitat de Catalunya. (2010). Currículum Educació Secundària Obligatòria. Departament d'Educació.

GREDICS (Grup de Recerca en Didàctica de les Ciències Socials). (2011). Descobrim la Torre Mapfre, descobrim Barcelona. Coordinació: Joan Pagès. 5 quaderns de treball i una guia didàctica. Barcelona: Mapfre.

Gomà, F. (1988). Antropologia del temps. En F. Gomà et al., El Temps, cicle de conferèncis (pp. 21-33). Barcelona: Fundació Caixa de Pensions.

Grup de Ciències Socials de "Rosa Sensat». (1981). Les Ciències Socials a la Segona Etapa d'EGB. Col. Rosa Sensat. Barcelona: Edicions 62.

Gruzinski, S. (2018). ¿Para qué sirve la historia? Madrid: Alianza Editorial.

Guitton, L. (2018). Apéndice. El historiador y los colegiales. En S. Gruzinski, ¿Para qué sirve la historia? (pp. 239-243). Madrid: Alianza Editorial,

Guldi, J. y Armitage, D. (2016). Manifiesto por la historia. Madrid: Alianza Editorial

Gutiérrez, M. C. y Pagès, J. (2018). Pensar para intervenir en la solución de las injusticias sociales. Pereira: Universidad Tecnológica de Pereira. Facultad de Ciencias de la Educación

Hinsdale, B. A. (1912). El estudio y la enseñanza de la historia. Madrid: Daniel Jorro editor.

Hodeige, M. (1981). Histoire et cours apparentés dans l'enseignement secondaire. Liège : Institut d'enseignement supérieur pédagogique de la Ville de Liège. Centre de la Pédagogie de l'histoire et des sciences de l'Home.

Hölscher, L. (2014). El descubrimiento del futuro. Madrid: Siglo XXI España.

ICEM-Pédagogie Freinet. (1984). Histoire partout, géographie tout le temps. Paris: Syros.

Innerarity, D. (2009). El futuro y sus enemigos. Una defensa de la esperanza política. Barcelona: Paidós. 
Jeffreys, M. V. C. (1959). History in schools. London: Pitman.

Jenkins, K. (2009). Repensar la historia. Madrid: Siglo XXI.

Johnson, M. (1976). Le concept de temps dans l'enseignement de l'histoire. Cahiers de Clio, 45-46, pp. 61-74.

Koselleck, R. (1993). Futuro pasado. Para una semántica de los tiempos históricos. Barcelona: Paidós.

Laurentin, E. (dir.). (2010). À quoi sert l'histoire aujourd'hui? Paris: Bayard Éditions.

Lautier, N. (1997a). À la reencontre de l'hitoire. Villeneuve d'Ascq: Presses Universitaires du Septentrion.

Lautier, N. (1997b). Enseigner l'histoire au lycée. Paris: Armand Colin.

Lowenthal, D. (1998). El pasado es un país extraño. Madrid: Akal.

Llusà, J. y Pagès, J. (2013). El pasado, el presente y el futuro en la innovación en la investigación en didáctica de la historia. Un estudio sobre la contemporaneidad. Reseñas de Enseñanza de la Historia, 11, pp. 11-28.

MacMillan, M. (2010). Juegos peligrosos. Usos y abusos de la historia. Barcelona : Ariel.

Marbeau, L. et al. (1974). Histoire diachronique et étude des milieux géographiques dans le cycle d'observation des C.E.S. expérimentaux ou chargés d'expérience. Paris: Institut Nationale de Recherche et de documentation pedagògiques.

Muñoz, E. y Pagès, J. (2012). La relación pasado-presente en la enseñanza de la historia en la educación secundaria obligatoria catalana. Clío \&Asociados. La Historia enseñada, 16, pp. 11-38.

Nidelcoff, M. T. (1971). La escuela y la comprensión de la realidad (Ensayo sobre la metodología de las ciencias sociales). Buenos Aires: Editorial Biblioteca.

Nidelcoff, M. T. (1979). ¿Maestro pueblo, maestro gendarme? Bogotá: Ecoe Ediciones.

Pagès, J. (1988). Situar-se en el temps, situar-se en la història. Guix, 124, pp. 11-16. 
Pagès, J. (1989). Aproximación a un currículum sobre el tiempo histórico. En J. Rodríguez Frutos (ed.), Enseñar historia. Nuevas propuestas (pp. 107-138). Barcelona: Laia/Cuadernos de Pedagogía.

Pagès, J. (coord.). (1995). Paisajes. Conocimiento del Medio 6. 3er ciclo de Educación Primaria de la Editorial Bruño. Ediciones para Andalucía, Canarias, Galicia, País Valenciano, País Vasco y territorio MEC.

Pagès, J. (1997a). El tiempo histórico. P. Benejam y Pagès (coords.), Enseñar y aprender ciencias sociales, geografía e historia en la educación secundaria (pp. 189-208). Barcelona: ICE Universitat de Barcelona/Horsori.

Pagès, J. (1997b). Los conflictos en las sociedades rurales: el conflicto remensa (s. XV) y el conflicto de Chiapas (1994). En P. Benejam y J. Pagès (coords.), Ciencias Sociales. Contenidos, Actividades y Recursos. Guías Praxis para el profesorado de ESO (pp. 415-480). Barcelona: Praxis.

Pagès, J. (1998). Una història per a les generacions del segle XXI: Els problemes de l'ensenyament i de l'aprenentatge de la història i els reptes del futur. Perspectiva Escolar, 224, pp. 2-12.

Pagès, J. (1999a). El tiempo histórico: ¿Qué sabemos sobre su enseñanza y su aprendizaje? Análisis y valoración de los resultados de algunas investigaciones. AA. VV., Aspectos didácticos de Ciencias Sociales 13 (pp. 241-278). Zaragoza: ICE-Universidad de Zaragoza.

Pagès, J. (1999b). Es necesario conectar los contenidos históricos con los problemas del presente. Novedades Educativas, 100, pp. 10-11.

Pagès, J. (2003). Ciudadanía y enseñanza de la historia». Reseñas de Enseñanza de la Historia, 1, pp. 11-42

Pagès, J. (2004a). Tiempos de cambios... ¿Cambios de tiempos? Sugerencias para la enseñanza y el aprendizaje del tiempo histórico a inicios del siglo XXI. En F. Ferraz (org.), Reflexôes sobre espaço-tempo. Coleçâo Textos de Graduaçâo, volume 3 (pp. 35-53). Universidade Católica do Salvador. Instituto de Filosofia e Ciéncias Humanas. Centro de Estudos do Imaginário Contemporâneo. UCSAL/ Quarteto editora. 
Pagès, J. (2004b). Com volem la Barcelona del futur? Proposta didàctica per l'estudi del passat, del present $i$ del futur de la ciutat. Institut d'Educació/Sector d'Urbanisme. Ajuntament de Barcelona.

Pagès, J. (2006). La comparación en la enseñanza de la historia. Clío y Asociados, 9-10, pp. 17-35.

Pagès, J. (2006). Catalunya i Espanya a Europa ahir, avui i demà. Unitat didàctica per commemorar el 20è aniversari de la integració de Catalunya i Espanya a Europa. 1 de gener de 1986-1 de gener de 2006. Ajuntament de Barcelona. Institut d'Educació.

Pagès, J. (2007). La educación para la ciudadanía y la enseñanza de la historia: cuando el futuro es la finalidad de la enseñanza del pasado. En R. M. Avila, R. López y E. Fernández (eds.), Las competencias profesionales para la enseñanzaaprendizaje de las Ciencias Sociales ante el reto europeo y la globalización (pp. 205-215). Bilbao: Asociación Universitaria del Profesorado de Didáctica de las Ciencias Sociales.

Pagès, J. (2009). Consciència i temps històric. Perspectiva Escolar, 332, pp. 2-8.

Pagès, J. y Casas, M. (2005). Republicans i republicanes als camps de concentració nazis. Testimonis i recursos didàctics per a l'ensenyament secundari. Barcelona: Institut d'Educació, Ajuntament de Barcelona.

Pagès, J., Nomen, J. y González, N. (2010). Dones del 36. Col. Memòria històrica de l'educació 2. Barcelona. Ajuntament de Barcelona Institut d'Educació. CD-Rom interactiu i quadernet.

Pagès, J. y Santisteban, A. (1999). La enseñanza del tiempo histórico: una propuesta para superar viejos problemas. En Asociación Universitaria del Profesorado de Didáctica de las Ciencias Sociales/Departamento de Ciencias Humanas y Sociales de la Universidad de La Rioja (eds.), Un currículum de Ciencias Sociales para el siglo XXI. Qué contenidos, para qué (pp. 187-207). Sevilla: Díada editora.

Pagès, J. y Santisteban, A. (2008). Cambios y continuidades: aprender la temporalidad histórica. En M. A. Jara (coord.), Enseñanza de la Historia. Debates y Propuestas (pp. 91-127). EDUCO Editorial de la Universidad Nacional del Comahue (Argentina). 
Pagès, J. y Santisteban, A. (2010). La enseñanza y el aprendizaje del tiempo histórico en la educación primaria. Cadernos CEDES, 30(82), pp. 278-309.

Prost, A. (2016). Doce lecciones sobre Historia. Granada: Comares.

Rüsen, J. (2007). Memory, history and the quest for the future. En L. Cajani (ed.), History Teaching, Identities and Citizenship (pp. 13-34). European Issues in Children's Identity and Citizenship, 7. CiCe. Stoke on Trent. Trentham Books.

Sala, S. (coord.). (2018). Programa de ciències socials de segona ensenyança de I'Escola Andorrana. Ministeri d'Educació i Ensenyament Superior. Govern d'Andorra. <https://www.educacio.ad/images/stories/estudis/2aEnsenyanca/ Prog2Ense_CienciesSocials.pdf> (consulta enero 2019).

Santisteban, A. y Pagès, J. (2006). La enseñanza de la historia en educación primaria. En M. Casas y C. Tomàs (coords.), Educación primaria. Orientaciones y recursos (pp. 468/129 a 468/160 y 468/159 a 468/183). Madrid: Editorial Práxis

Simián de Molinas, S. (1970). El método retrospectivo en la enseñanza de la historia. Buenos Aires: Angel Estrada. 